El Neo-Rococó en la creación de la(s) nación(es) Tobias Locker Boletín de Arte (N. $\left.{ }^{\circ} 19\right)$, e008, septiembre 2019. ISSN 2314-2502

https://doi.org/10.24215/23142502e008

http://papelcosido.fba.unlp.edu.ar/ojs/index.php/boa

Facultad de Bellas Artes. Universidad Nacional de La Plata

La Plata. Buenos Aires. Argentina

\title{
EL NEO-ROCOCÓ EN LA CREACIÓN DE LA(S) NACIÓN(ES)
}

\section{THE NEO-ROCOCO IN THE CREATION OF THE NATION(S)}

\author{
Tobias Locker \\ tobias.locker@gmail.com \\ IDEX Cross Disciplinary Program (CDP). Patrimalp. Université Grenoble Alpes. Francia \\ Recibido: 7/3/2019 \\ Aceptado: 14/6/2019
}

\section{RESUMEN}

El Rococó vio un renacimiento en el siglo XIX y se convirtió, junto con otros estilos del Antiguo Régimen, en una referencia para las élites (antiguas y emergentes) en ambos lados del Atlántico. Este artículo pretende mostrar cómo interiores y muebles, a primera vista objetos sobre todo decorativos, adquirieron en el pasaje del siglo XIX al XX distintos sentidos semánticos en el marco del ser nacional, a la par de la formación de las narrativas históricas de los estados-nación. Partiendo de un conjunto de muebles realizados en Prusia se explica cómo estos artefactos se convirtieron en armas ideológicas en la batalla por la hegemonía de la cultura entre Francia y el Imperio alemán durante la Exposición Universal de París de 1900.

\section{PALABRAS CLAVE}

Neo-Rococó; Exposición Universal 1900; Julius Zwiener; François Linke; Buenos Aires

\section{ABSTRACT}

The Rococo underwent a revival in the 19th century and became, along with other styles of the Ancient Regime, a reference for (old as well as emerging) elites on both sides of the Atlantic. This article aims to show how interiors and furniture, considered first and foremost decorative objects, acquired at the turn from the nineteenth to the twentieth century different semantic meanings within the context of nation building. Starting with a group of Prussian furniture, it explains how these artefacts became ideological weapons in the battle for cultural hegemony between France and the German Empire during the 1900 Universal Exhibition in Paris.

\section{KEYWORDS}

Rococo Revival; Universal Exhibition 1900; Julius Zwiener; François Linke; Buenos Aires 
Dentro del historicismo del siglo XIX, el Neo-Rococó se convirtió, al igual que otros estilos del Antiguo Régimen, en una tendencia del interiorismo en boga, tanto para el espacio público como para el privado. ${ }^{2}$ París, metrópolis de la moda del continente europeo desde el siglo XVIII, seguía marcando el ritmo del gusto. Por ello, importantes figuras como Henry Dasson (1825-1896) o Louis-Auguste y Alfred-Emmanuel Beurdeley (1808-1882 y 1847-1919, respectivamente) establecieron sus empresas en la ciudad y se especializaron en muebles de lujo. Así, exploraron los estilos relacionados con el Antiguo Régimen (Luis XIV, Luis XV y Luis XVI) y produjeron mobiliario historicista con gran éxito durante el Segundo Imperio Francés. Las referencias a dicho período histórico y al suntuoso carácter de sus muebles - constituido por la calidad y el valor estético de sus materiales-, respondían, sobre todo hasta las primeras décadas del siglo XX, tanto a las necesidades de las antiguas élites (aristocráticas), como a las nuevas (industriales y burguesas), que buscaban expresar su posición social y sus aspiraciones a través del consumo de productos de lujo, abarcando desde ostentosos interiores, hasta variados objetos de artes decorativas. ${ }^{3}$

La popularidad creciente del Neo-Rococó entre esos sectores sociales se podía percibir públicamente, sobre todo, en el marco de las exposiciones internacionales, en donde era visible su longevidad como tendencia dentro de un eclecticismo internacional floreciente. La sinuosidad de sus formas y ornamentos y su predilección tanto por el artesanado de gran calidad como por materiales exclusivos, permitían en la segunda mitad del siglo XIX una fusión con el emergente estilo modernista o Art Nouveou y su adopción al gusto más contemporáneo en múltiples rincones del mundo. ${ }^{4}$

Dentro del mercado de lujo en el último tercio del siglo XIX, el negocio de muebles de lujo de Joseph-Emmanuel Zwiener (ca. 1848, activo hasta 1895), establecido en París, ejemplifica claramente la nueva actualidad que tomó el Neo-Rococó. Así, en la Exposición Internacional de 1889 realizada en París recibió la medalla de oro por un armario de gabinete que fundía el espíritu del Neo-Rococó con las líneas sinuosas del emergente Art Nouveou. ${ }^{5}$ La relevancia del premio y su prestigio suscitó el interés del emperador Guillermo II de Alemania, que adquirió a través del historiador de arte Paul Seidel diversos muebles realizados por el artesano. ${ }^{6}$ Este contacto con la familia imperial fue el comienzo de una intensa relación de la familia Zwiener con el Imperio Alemán. En 1895, cuando Joseph-Emmanuel vendió su negocio a Jean-Henri Jansen y se retiró, invirtió parte de sus ingresos en la empresa de su hermano menor, Julius Zwiener (1867-1922), quien había decidido trasladarse de París a Berlín (Meiner, 2014). Probablemente, el joven ebanista había sido reclutado en nombre del emperador Guillermo II y pretendía aprovechar el prestigio y los importantes encargos que suponía trabajar cerca de la corte imperial alemana (Locker, 2017).

2 El primer resurgimiento del Rococó (también denominado "segundo rococó») tuvo lugar en Francia durante el reinado de Luis Felipe I (1830-48) y, de allí, se extendió a otros países europeos (Véanse Dion-Tenenbaum, 1990; Haaff, 2004; Zweig, 1924).

3 Thorstein Veblen acuñó en su análisis el término consumo ostentoso (conspicuous consumption) para este tipo de comportamiento socioeconómico. Si bien el término describe el consumo ostentoso de bienes, cuya mayor calidad proviene de varios factores, entre ellos el valor artístico, también puede aplicarse al comportamiento de consumo de la rica burguesía industrial, que copió los patrones de distinción social de las clases más antiguas establecidas (Véase: Veblen [1899] 1995).

4 El Neo-Rococó cobró también un nuevo impulso en las corrientes historicistas de la segunda mitad del siglo XIX (el denominado «tercer rococó»), sobre todo en el sector del lujo (Ireland, 2006; Horváth, 2016). 5 El mueble fue vendido por Christie's el 17 de marzo de 2011 en Londres (Christie's, 2011). El triunfo del nuevo estilo orgánico resulta evidente si consideramos que Émile Gallé, uno de los padres fundadores de la École de Nancy, recibe al mismo tiempo el gran premio por su obra en vidrio, una medalla de oro por su cerámica y una medalla de plata por sus muebles.

6 La documentación de estas adquisiciones se puede consultar en: Geheimes Staatsarchiv Preussischer Kulturbesitz (GStPK), Berlin-Dahlem (signatura: BPH, Rep. 192, NI. Seidel Nr. 74, fol. 31-33). 


\section{LAS ARTES DECORATIVAS COMO MUNICIÓN IDEOLÓGICA}

En el mismo año que Julius Zwiener llegó a Berlín, Seidel publicaba un importante hallazgo. Al estudiar las Artes Decorativas bajo el reinado de Federico II, había podido identificar a Johann Melchior Kambly (1718-1784) ${ }^{7}$ como el principal fabricante de monturas de bronce dorado y muebles reales (Seidel, 1895). Este escultor decorativo había viajado en 1743 de Suiza a Potsdam para trabajar para Federico II, quien destinaría grandes sumas para renovar y ampliar diferentes palacios heredados y para construir otros nuevos, en los cuales se manifestaba un estilo Rococó particular, que se denomina Rococó Federiciono. ${ }^{8}$ De hecho, un descubrimiento como este tuvo implicaciones mayores: los muebles de Kambly, de una altísima calidad artística y artesanal y decorados con suntuosa decoración de bronce dorado (y a veces plateado), habían sido considerados, hasta ese momento, productos franceses; su identificación e interpretación como objetos distintivamente prusianos - no copias según los modelos franceses - ofrecía la oportunidad de destacar una tradición alemana específica que rechazaba el argumento de la subyugación de los alemanes al gusto francés.

Así, el artículo de Paul Seidel celebraba dentro de la producción artística de la Prusia del siglo XVIII, los muebles y bronces dorados de Johann Melchior, los comparaba con la producción contemporánea francesa y enfatizaba el nivel de igualdad, en un campo generalmente dominado por los franceses. Esta visión, que exaltaba el pasado prusiano, debe ser comprendida en relación con la tendencia historiográfica del siglo XIX denominada «borussiana», que glorificaba a Prusia como el salvador de la nación alemana, visible con la unificación alemana en 1871 (Doering-Manteuffel, 2001). Dentro de esa narrativa, el rey Federico II, que había puesto su reino en pie de igualdad con las primeras potencias europeas, se convirtió en una figura clave. Al crear y alimentar el mito de «Federico el Grande» los historiadores del arte se centraron en la producción artística bajo su reinado, descubriendo y subrayando las particularidades de los interiores decorativos del rey. Su destacada calidad y la de los objetos que los componían, convertían las denominadas artes decorativas «Federicianas» en vehículos visuales que podían ser utilizados como material argumentativo en la construcción de la nación alemana.

Mientras que hoy al analizar la producción de Kambly se hace hincapié en los contactos entre el Rococó francés y el Rococó Federiciono que sus obras permiten observar, las contribuciones de Seidel a la historiografía del arte de su tiempo ponían, sobre todo, énfasis en las diferencias. ${ }^{9}$ Además, este autor no solo miraba hacia atrás, sino que proyectaba hacia el futuro. A la luz de una industria artística de las artes decorativas en auge en el Imperio Alemán, Seidel utilizaba la obra de Kambly como definitiva precursora de la producción nacional contemporánea de bronce. Asimismo, terminaba su artículo con la desafiante afirmación de que Berlín podía proporcionar en 1895 «todo lo que hasta ahora sólo se podía encontrar en París» (Seidel, 1895, p. 60). ${ }^{10}$

Tal vez fuera solo una coincidencia que Julius Zwiener se instalara ese mismo año en Berlín. 0 , quizás, el hecho de que Seidel se convirtiera un año más tarde en director del prestigioso

7 Kambly fue bautizado el 18 de febrero de 1718 en la iglesia Predigern y murió el 12 de abril de 1784 en Potsdam; véase: Stadtarchiv Zürich (signatura: VIII.C.35. Tauf- und Ehenbuch Predigern 1668-1793) y GStAPK (signatura: VIII. HA, MKB, no. 574, 664).

8 Este estilo se manifestó, sobre todo, en sus decoraciones interiores. Utilizando varias influencias (francesas, holandesas e italianas) se independiza rápidamente de los modelos franceses y se perpetúa cronológicamente más tiempo que en Francia (todo el reinado de Federico II: 1740-1786), incluyendo en su fase tardía influencias clasicistas - entonces de moda en Europa - sin perder el aspecto Rococó general.

9 Este historiador publicaba regularmente todo en la prestigiosa revista Hohenzollern-Jahrbuch. Además fue autor de varios libros en los que dedicaba una especial atención a las artes del tiempo de Federico II. Véase Seidel, 1912.

10 «Die es zweifelloslässt, dassaufdiesem Gebiete in Berlin alles geleistet wardenkann, was bisher nur in Paris gesucht wurde» (Seidel, 1895, p. 60). Traducción del autor del artículo. 
Museo Hohenzollern de la ciudad fuera un reconocimiento a los servicios prestados al imperio por participar en el impulso de su industria artística, que también había acabado por convencer a Zwiener de venir. Sea como fuere, para el aparato nacional alemán fue muy oportuno que Julius Zwiener no solo aportara sus conocimientos - ya que había trabajado varios años para su hermano en París y había aprendido el arte del cincelado y el tratamiento al fuego de los bronces dorados-, sino que también aportara su prestigioso apellido. Este otorgaba glamour a la industria alemana de bronces y de muebles de lujo, lo que la hacía más competitiva frente a la producción francesa de prestigio internacional (Seidel, 1901). Aun habiéndose formado en Francia, Julius había nacido en Silesia, territorio perteneciente al Imperio Alemán, lo que facilitó la interpretación de sus muebles como específicamente alemanes.

Todos estos aspectos se harían visibles unos años más tarde en la Exposición Universal de París de 1900 (Locker, 2017). Allí Julius Zwiener exhibiría un prestigioso conjunto de muebles que había fabricado para el emperador Guillermo II (Baer, 1989). Presentado en la sala XIII del grupo XII (Decoración e interiores de edificios públicos y locales residenciales) de la Esplanade des Invalides (Witt, 1900), consistía en una cama con armarios y mesillas de noche, barnizados con exquisitas imágenes florales y adornados con monturas de bronce dorado [Figura 1]. La decisión de exponer este conjunto formaba parte de una estrategia que buscaba demostrar la igualdad alemana -si no la superioridad- en un campo de producción artesanal, dominado por los franceses. Esta apuesta pretendía subrayar la alta calidad de la producción artística contemporánea y, de hecho, fue premiada en la competición industrial oficial con la medalla de oro.

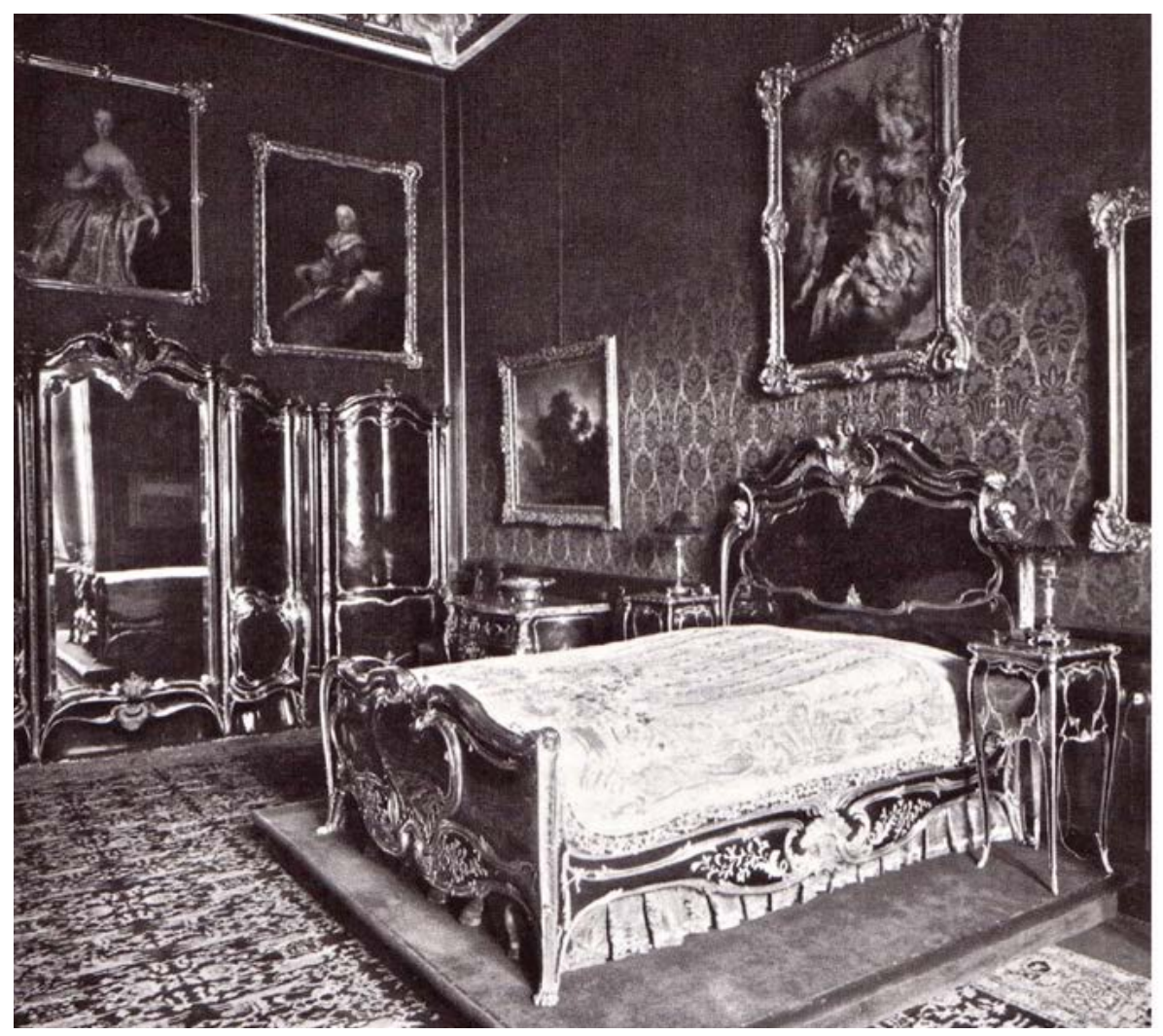

Figura 1. Foto de los muebles de Julius Zwiener en el dormitorio imperial (sala 208) del Palacio Real de Berlín, hacia 1905 (Meiner, 2014)

No obstante, no fue la única iniciativa. Las obras de Zwiener fueron acompañadas de un programa cultural, especialmente concebido para el gusto francés: la exposición Las colecciones de Federico el Grande, expuestas por orden supremo de su majestad el Emperador alemón, comisariada por Seidel en el pabellón alemán, presentaba las colecciones de arte francés del soberano (Seidel, 1900). A primera vista esta contribución tan importante del pabellón exhibía 
el arte Barroco y el Rococó francés, en un gesto de concordia y con la intención de mantener controladas las animosidades que existían desde la derrota francesa de 1871 en la guerra franco-prusiana. Sin embargo, las piezas se presentaban en un entorno que recreaba los interiores en los que Federico II había vivido y trabajado - mostrando, entre otros, también los muebles de Kambly-. Dado que el carácter específicamente Federiciano de las mismas fue especialmente destacado en el catálogo del pabellón (publicado en francés, inglés y alemán), parece evidente que el arte francés fue utilizado como caballo de Troya para también presentar los interiores decorativos de la grandeza de Prusia. De esta manera, si bien la colección francesa expuesta fue dotada de un contexto histórico, fue también utilizada para presentar -y exponer- el argumento de Seidel sobre la existencia de una tradición Rococó alemana específica. Entonces, se podría entender que la exhibición de los muebles Neo-Rococó de Zwiener era solo una parte de la estrategia de prestigio del Imperio Alemán, que se completaba con la exposición del pasado histórico.

Al año siguiente, el propio Seidel daba su versión de los hechos en un libro de claras ambiciones propagandísticas titulado Muebles de Arte y Bronce en la Exposición Mundial de París de 1900 creados para Su Majestad el Emperador Alemón (1901). Esta publicación ricamente ilustrada explicaba a los lectores alemanes el enorme éxito del que había gozado en París la producción artística imperial. Su texto conectaba la industria de las artes decorativas contemporáneas con la producción histórica alemana y presentaba la obra de Kambly como el antepasado de una producción independiente y decisivamente prusiana. Así, al mencionar que el rococó de Federico II «puede ser fácilmente distinguido de cualquier logro similar en Alemania o Francia», Seidel no se olvidaba de subrayar, sobre la base de sus recientes investigaciones, la independencia estilística del "particular estilo de Potsdam» (1901, p. 10). ${ }^{11}$

Aunque no se puede negar el gran éxito del pabellón alemán de 1900, en Francia la campaña de propaganda exquisitamente diseñada no fue reconocida al nivel que los alemanes hubieran esperado. De hecho, los franceses usarían una estrategia parecida con respecto a su pasado histórico (Lasc, 2017) y por esto solo unos pocos aceptaban la versión alemana, como el crítico de arte Gustave Babin, quien escribía en la Revue Illustrée: «Reconocerlo puede costar o no a nuestra autoestima nacional, pero los verdaderos triunfos de la Exposición de 1900, en general, fueron los alemanes» (1900, s. p.)..$^{12}$ La mayoría de los franceses elogiaba solo la mencionada exposición pero no reconocía el argumento de Seidel, según el cual la producción alemana de muebles de lujo tenía sus propias raíces. En su lugar, ratificaba la subyugación alemana a la francesa, como por ejemplo Émile Berr, que afirmaba: «todos los elementos de esta decoración son tomados del arte francés. Federico hizo fabricar los muebles según modelos franceses bajo la dirección de trabajadores franceses» $\left(900\right.$, p. 176). ${ }^{13}$

Por lo tanto, si bien la autopresentación del Imperio Alemán en la Exposición Universal de París tuvo éxito, la estrategia que buscaba el reconocimiento francés de su industria de decoración de interiores como igual, solo lo tuvo en parte. Mientras unas pocas personalidades, como Babin, podían ver más allá de la autoestima nacional y centrarse en cuestiones de calidad, muchos otros, como era de esperar, simplemente rechazaron todos los argumentos que hubieran permitido a los alemanes verse y presentarse al mismo nivel que los franceses. Así, en la valoración general sobre la Exposición Universal de París, Berr subrayaba el aporte

11 «Auch hier bildete sich ein eigener Potsdamer Stil aus, der von allen ähnlichen Leistungen in Deutschland und Frankreich, namentlich auch dem süddeutschen Rokoko, leicht unterschieden werden kann» (Seidel, 1901, p. 10). Traducción del autor del artículo.

12 «ll peut, ou non, en coûter à notre amour-propre national de le reconnaître, mais les vrais triomphateurs de l'Exposition de 1900, dans l'ensemble, ce furent les Allemands» (Babin, 1900, s/p). Traducción del autor del artículo.

13 «Tous les éléments de cette décoration ont été empruntés à l'art français; Frédéric avait fait exécuter ce mobilier d’après des modèles et sous la direction d'ouvriers français» (Berr, 1900, p. 176). Traducción del autor del artículo. 
de su compatriota François Linke (1855-1946), que expuso un reloj excepcional de éxito internacional; mientras que Seidel, enfatizaba la importancia del dormitorio de Zwiener (Payne, 2003). No obstante, el Ropports du Jury International de 1900 mencionaba tanto a Zwiener como a Linke como ganadores de una medalla de oro ex aequo (Neveux, 1902).

\section{AUTOPERCEPCIÓN(ES): LO NACIONAL Y LO COLONIAL}

Si bien la instrumentalización consciente de las artes decorativas en la configuración de la identidad nacional es extremadamente visible en los casos de Zwiener y Linke, la carga ideológica de estos artefactos suele pasar desapercibida en otros contextos menos connotados políticamente. El papel que los interiores han desempeñado en el impase del siglo XIX al XX no solo debe reducirse a la creación de prestigio doméstico o familiar, sino que participa del complejo simbólico de construcción del Estado-nación. Además, el valor cultural de estos interiores traspasó los espacios geográficos europeos - y la mera querella entre Alemania y Francia- para participar de la red transnacional de intercambio capitalista, que hacía circular divisas, objetos y también modelos culturales. Por tanto, el Neo-Rococó tuvo un papel a desempeñar en la construcción de las jóvenes identidades nacionales en diferentes países de América Latina.

Utilizado para decoraciones de interiores, privadas o informales, pero también para la elaboración de espacios con una elevada función social, como salones de baile y de música, el Neo-Rococó resultó de interés para las élites económicas de América. Un ejemplo visible se puede encontrar en la sala de baile del Palacio Errázuriz de Buenos Aires [Figura 2].

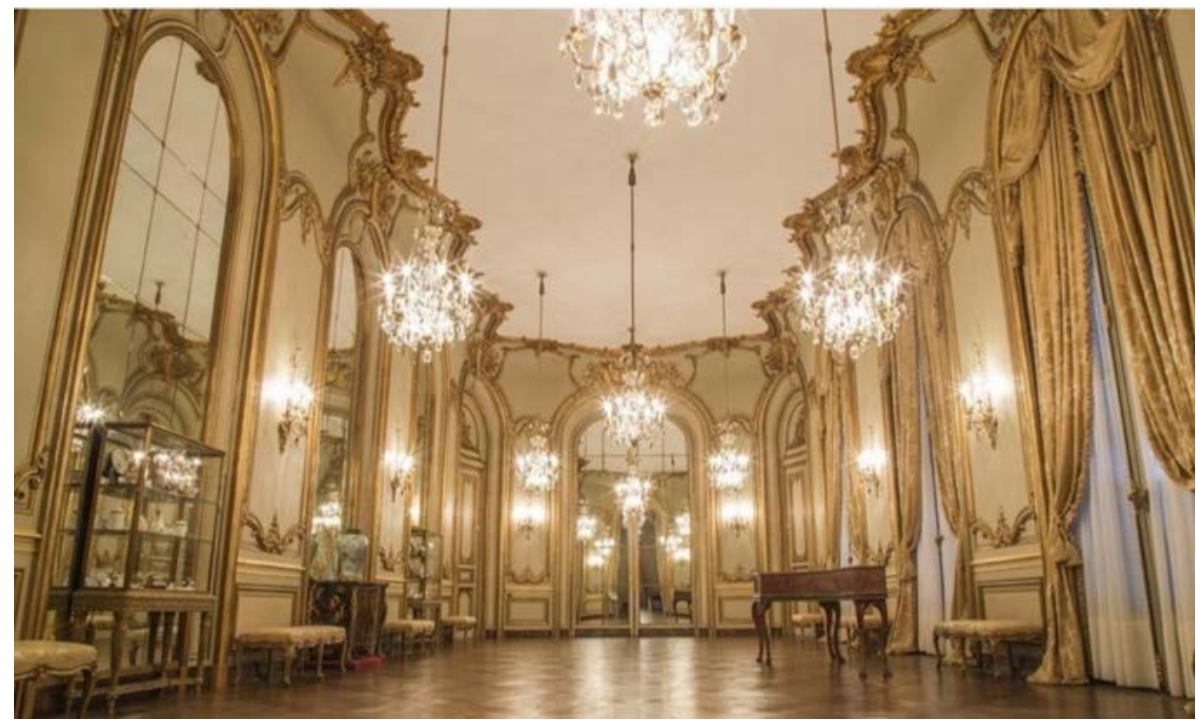

Figura 2. Sala de baile de en el Palacio Errázuriz, Ciudad Autónoma de Buenos Aires, Argentina. Foto del autor

Dicho edificio, en la actualidad alberga el Museo Nacional de Artes Decorativas (MNAD), fue diseñado en 1911 por el arquitecto francés René Sergent (1865-1927) para el diplomático chileno Matías Errázuriz Ortúzar y su mujer Josefina de Alvear, como hôtel particulier. La sala de baile, a diferencia de la mayoría de los cuartos de la misma residencia que retoman otros estilos del Antiguo Régimen, cita el estilo Régence francés, es decir, la primera época del Rococó. La estructuración más clásica barroca, visible en las paredes donde largas ventanas, puertas y espejos arqueados alternan con grandes revestimientos de madera, otorga a la sala un carácter de grandeza formal; este se disuelve en la zona transitoria entre pared y techo con sus estucos decorativos de una sensibilidad sinuosa Rococó, lo que da al ambiente una noción más lúdica e informal. ${ }^{14}$

14 La sala de baile está claramente inspirada en las invenciones de Germain Boffrand (1667-1754) para el Salón Oval del Hôtel de Soubise en París realizado a partir de 1736. 
Aunque a primera vista esta sala parezca responder a las preferencias estilísticas personales de la familia más que a la construcción de la identidad nacional, la elección de este estilo - -junto al resto de lenguajes tomados del Antiguo Régimen- habla también de la autodefinición del diplomático chileno, en una época en que las naciones latinoamericanas se estaban formando. Los antepasados de Matías Errázuriz Ortúzar y de su mujer Josefina de Alvear habían llegado de Europa a América en el siglo XVIII. La utilización de historicismos de la misma época tenía un valor simbólico dirigido a subrayar un pedigrí europeo; un mensaje dirigido a la oligarquía nacional altamente internacionalizada, que compartía el mismo sistema de referencias (Bradford Burns, 1980).

El caso del Palacio Errázuriz es un ejemplo de una tendencia generalizada entre las élites latinoamericanas, completamente al corriente de la moda creada en el otro lado del Atlántico. Si su fortuna lo permitía, no solo entregaban el diseño de sus futuras residencias a arquitectos europeos - aunque luego fuera ejecutado por profesionales locales (Gutiérrez, 1984)—, sino que también consumían mercancías de lujo europeas - consumo conspicuo en términos de Veblen- ${ }^{15}$ para distinguirse del resto. Un buen ejemplo de este comportamiento es el banquero Antonio Devoto (1832-1916) y su segunda mujer Elina Pombo, que habían adquirido entre 1909 y 1921 cuarenta muebles de François Linke, el ya mencionado antagonista francés del berlinés Zwiener. Los muebles se destinaron a la decoración de su nueva residencia principal en Buenos Aires, edificada bajo la dirección del arquitecto ítalo-argentino Juan Antonio Buschiazzo (1845-1917) en el estilo Barroco italiano. ${ }^{16}$ El palacio tenía casi doscientas habitaciones decoradas por los más conocidos artistas y artesanos europeos, en una mezcla ecléctica con citas recurrentes a la grandeza europea - ya en declive - que servía, además, para subrayar los antecedentes europeos de los propietarios. ${ }^{17}$ Entre los muebles de Linke se encontraba un suntuoso conjunto Neo-Rococó, encargado en 1913, de líneas cercanas al conjunto imperial de Zwiener presentado en 1900 [Figura 3].

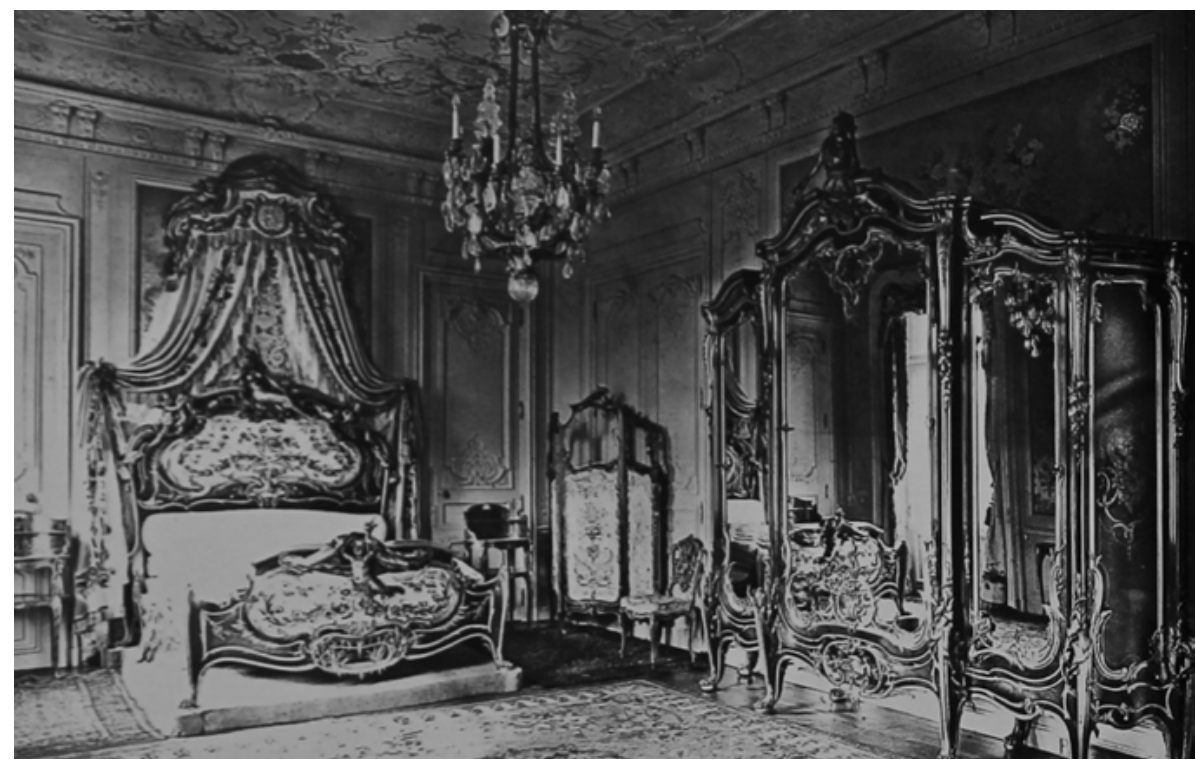

Figura 3. Los muebles que François Linke había vendido a Antonio Devoto y Simón Iturri Patiño, foto del dormitorio de Patiño en París después de 1924 (Payne, 2003)

15 Véase nota 3.

16 La residencia fue erigida en Villa Devoto, barrio residencial burgués creado en 1888 y que lleva el nombre de su fundador, Antonio Devoto. El palacio fue destruido después de 1938 (Herz, 1978).

17 Devoto nació en Italia y emigró en 1854 a la Argentina donde hizo su fortuna (Scarzanella, 1991).

18 Entre 1906 y 1916 el matrimonio Errázuriz había residido en Francia, lo que favoreció a las misiones diplomáticas de Matías. Antonio Devoto conocía también el estilo de vida de la burguesía europea por sus viajes como presidente del Banco de Italia y Río de la Plata. 
Las citadas residencias en Buenos Aires enfatizaban en su decoración los lazos culturales con el continente europeo para subrayar los árboles genealógicos de los ilustres propietarios. El gusto, tanto de la familia Errázuriz Ortúzar como de la Devoto, por el estilo de vida euro-continental ciertamente se intensificó, pues ambas cruzaron múltiples veces el Atlántico por negocios y vivieron un tiempo en Europa. ${ }^{18}$ Si asumimos estas aficiones y preferencias, sobre la base de un conjunto de estilos que servían para glorificar las élites del Antiguo Régimen, ciertas facetas estéticas y simbólicas de la cultura colonizadora europea se insertan en la formación de la identidad nacional (Bradford Burns, 1980; Daughton, 2008). Tanto Ortúzar como Devoto formaban parte de las oligarquías de sus respectivas naciones, por lo que tenían, frente a los otros grupos sociales, un papel preponderante en la construcción de la identidad nacional. (Cockcroft, 2001). El cosmopolitismo internacional de la creciente nación se contraponía a las raíces indígenas, que fueron, por ejemplo, devaluadas por figuras prominentes como Domingo Faustino Sarmiento, con su despreciativa visión de la cultura gaucha en Argentina. ${ }^{19}$ En este contexto, los muebles -aunque a primera vista pudieran parecer solo objetos decorativosno deben ser interpretados solamente como expresiones artísticas de valor estético fijo, sino también como objetos históricos que testimonian la autoimagen de los representantes de la clase dirigente «de Buenos Aires, que vivían mirando a Europa y ansiosos de importar las últimas ideas [...] para dar con ellas la forma a su nación sea cual fuese el costo» (Shumway, 1993, p. 96).

Así, y en última consecuencia, estas importaciones decorativas con siluetas sinuosas, estucos, rocallas asimétricas y opulentos dorados, deben ser vistas como adopción simbólica de los antecedentes coloniales europeos del Antiguo Régimen, pero también como manifestaciones del gusto de la época, para distinguirse socialmente (Bourdieu, 1984). Este gusto se integraba en el «habitus» de toda una clase dirigente que aportaba, con estas referencias, valores simbólicos de status y representación social de las élites; una clase fuertemente implicada en la construcción de la comunidad imaginada del proyecto nacional (Anderson, 2006; Itzigsohn \& vom Hau, 2006). Los casos de Errázuriz y Devoto, que subrayan la herencia europea de su linaje a través de los objetos, responden directamente a esta constelación.

No obstante, la multiplicación de interiores rococó en el albor de las naciones, no responde simplemente a un interés de reforzar la herencia europea directa de la familia. Dichas filiaciones o raíces verdaderas no eran necesarias para su generalización en interiores de la época. En cierto modo, el rococó se convirtió en una tradición inventodo que intentaba «establecer continuidad con un pasado histórico adecuado» (Hobsbawm, 1983, p. 1)..$^{20}$ En concreto, el conjunto Neo-Rococó que Linke vendió en 1913 a los Devoto fue originalmente creado para la residencia parisina del magnate Simón Iturri Patiño (1862-1947) y su mujer Albina Rodríguez Ocampo [Figura 3]. Este barón boliviano del estaño llegó con fortuna, espíritu comercial y cierta habilidad, a ser uno de los hombres más ricos del mundo en su tiempo. Probablemente de orígenes mestizos y muy modestos, se sirvió también de las artes y de la cultura para darse ese pedigrí. ${ }^{21}$ El deseo de superar esos supuestos orígenes contribuyó a su intento de mimetizar gestos culturales de una de las antiguas potencias coloniales, a través del consumo de muebles de lujo.22 De hecho, Linke diseñó el mencionado conjunto Neo-Rococó especialmente

19 La toma de partido se manifiesta claramente en la declaración: «Buenos Aires puede volver a ser lo que fue, porque la civilización europea es tan fuerte allí, que a despecho de las brutalidades del gobierno se ha de sostener» (Sarmiento, [1845] 2007, p. 69).

20 «Attempt to establish continuity with a suitable historic past» (Hobsbawm, 1983, p. 1). Traducción del autor del artículo. Por la conexión entre gusto y consumo cultural véase Baldasarre, 2006.

21 Casi no hay información sobre los orígenes de Simón Iturri Patiño, los cuales son muy debatidos. Mientras algunos los destacan como modestos, subrayando, entre otros, su aspecto físico de reminiscencias indígenas (ver por ejemplo: Lenoir, 1958), otros subrayan un linaje hispánico, basándose, sobre todo, en la etimología de sus apellidos (ver biografía «oficial» de Charles Geddes [1984], colaborador de Patiño durante 37 años). 22 Sobre el concepto de mimetismo en el contexto colonial, véase Bhabha [1984]. Francia también tiene una larga historia colonial en América. Todavía en la actualidad varias islas del mar Caribe pertenecen como departamentos (o colectividades) de ultramar a su territorio «nacional». Los más conocidos son Martinica y Guadalupe. 
para Patiño, evocando el dormitorio imperial de Zwiener [Figura 1]. La filiación de ambas obras es bien visible en la repetición de las formas distintivas de la cama (cabecero y piecero) y del armario (la distintiva división tripartida) del Emperador, un hecho que, sin duda, habría sido celebrado por los alemanes - aunque los objetos de Linke presentan una riqueza de bronces más acentuada [Figura 3]-. De este modo, con un diseño de orígenes imperiales, como el realizado por Linke, el conjunto le servía a Iturri Patiño para legitimar su figura, junto con la de sus herederos, dentro de la alta sociedad en su propio país y, a la vez, para participar de los códigos visuales de las oligarquías financieras latinoamericanas (Crandon-Malamud, 1991).

Para concluir, los ejemplos Neo-Rococó analizados no solo demuestran que este estilo se había convertido, en el paso del siglo XIX al XX, en una referencia para las élites a ambos lados del océano Atlántico - fueran provenientes de familias con linaje o ricos emergentes-, sino que su uso puede entenderse más allá de sus meros rasgos decorativos. Estas piezas jugaron un papel en la configuración de una tradición histórica y una semántica simbólica imprescindible en la construcción de los Estados-nación. En el caso de los muebles de Zwiener, el Imperio Alemán enfatizó una nueva relación con el pasado en la Exposición Universal de París de 1900, al engarzar la producción de muebles bajo el reinado de Federico II de Prusia a la nueva configuración nacional del Imperio Alemán.

Asimismo, al identificar a Kambly como antecesor e iniciador de una tradición distintiva en las artes decorativas alemanas, con Zwiener como su legítimo continuador, pretendían arrebatar la primacía simbólica a Francia y poner la producción artística alemana - y por ende la nacióna la altura de la francesa. Aunque el reconocimiento francés nunca llegó, la estrategia desarrollada sí caló en el ámbito alemán, demostrando su éxito para la autopercepción y cohesión del ser nacional y su cultura. En comparación, los ejemplos latinoamericanos mencionados no fueron coordinados por el Estado per se, sino por individuos de las élites económicas - que estaban en ese momento construyendo el Estado-. El consumo ostentoso de productos de lujo mostraba la comprensión de la representación social de estas élites, a través de una tradición cultural europea distintiva, que sobrepasaba las raíces personales. De este modo, muebles y decoraciones de interiores Neo-Rococó no solo eran expresiones del gusto, sino que deben entenderse también como indicadores culturales, sociales, económicos y raciales participantes en la configuración del ser nacional y en la creación de la(s) nación(es) en el pasaje del siglo XIX al XX.

\section{REFERENCIAS}

Anderson, B. (2006). Imagined communities. Reflections on the Origin and Spread of Nationalism. [Comunidades imaginadas. Reflexiones sobre el origen y la difusión del nacionalismo]. Nueva York, Estados Unidos: Verso.

Babin, G. (1900). La Participation de l'Allemagne à l'Exposition de 1900 [La participación de Alemania en la Exposición de 1900]. Revue illustrée, (24).

Baer, W. (1989). Eine Schlafzimmer-Ausstattung von Julius Zwiener. Ein Auftrag Koiser Wilhelms II. für das Berliner Schloss, 1895-1900 [Un dormitorio por Julius Zwiener. Un encargo del emperador Guillermo II para el Palacio de Berlín, 1895-1900]. Berlín, Alemania: Kulturstiftung der Länder.

Baldasarre, M. I. (2006). Los dueños del arte. Coleccionismo y consumo cultural en Buenos Aires. Ciudad Autónoma de Buenos Aires, Argentina: Edhasa.

Berr, E. (1900). Une idée du Guillaume II [Una idea de Guillermo II]. En L'Exposition de Paris 1900 [La exposición de París 1900] [Catálogo de exposición] (pp. 175-176). París, Francia: Montgredien. 
Bhabha, H. (1984). Of Mimicry and Man: The Ambivalence of Colonial Discourse [Del mimetismo y del hombre: La ambivalencia del discurso colonial]. October. Discipleship: A Special Issue on Psychoonalysis, (28), 125-133.

Bourdieu, P. (1984). Distinction. A Social Critique of the Judgement of Taste. Cambridge, Reino Unido: Harvard University Press.

Bradford Burns, E. (1980). The Poverty of Progress: Latin Americo in the Nineteenth Century. Los Angeles, Estados Unidos: University of California Press.

Cockcroft, J. D. (2001). América Latina y Estados Unidos: Historia y política país por país. Ciudad Autónoma de Buenos Aires, Argentina: Siglo Veintiuno.

Crandon-Malamud, L. (1991). From the Fat of Our Souls. Social Change, Political Process and Medical Pluralism in Bolivio [De la grasa de nuestras almas. Cambio Social, Proceso Político y Pluralismo Médico en Bolivia]. Berkeley, Estados Unidos: University of California Press.

Christie's. (2011). 500 Years: Decorative Arts Europe. Recuperado de https://www. christies.com/lotfinder/Lot/a-highly-important-french-ormolu-mounted-kingwood-tulipwood-5415761-details.aspx

Daughton, J. P. (2008). When Argentina was «French»: Rethinking Cultural Politics and European Imperialism in Belle-Époque Buenos Aires [Cuando Argentina era «francesa»: Repensar las políticas culturales y el imperialismo europeo en Belle-Époque Buenos Aires]. The Journal of Modern History, 80(4), 831-864.

Dion-Tenenbaum, A. (1990). Le Style Louis-Philippe [El estilo Luis-Philippe]. París, Francia: Flammarion.

Doering-Manteuffel, A. (2001). Die Deutsche Frogeund das Europäische Stoatensystem 18151871 [La pregunta alemana y el sistema de estados europeos 1815-1871]. Múnich, Alemania: oldenbourg.

Geddes, C. F. (1984). Patiño. Rey del estoño. Madrid, España: A.G. Grupo.

Gutiérrez, R. (1984). Arquitectura y urbanismo en Iberoamérica. Madrid, España: Cátedra.

Haaff, R. (2004). Louis-PhilippeMöbel. Möbel des Historismus [Muebles Luis-Philippe. Muebles del Historicismo]. Stuttgart, Alemania: Arnoldsche Art Publishers.

Herz, E. (1978). Villa Devoto. Un Barrio de quietud patriarcal. Ciudad Autónoma de Buenos Aires, Argentina: Municipalidad de la Ciudad de Buenos Aires.

Hobsbawm, E. (2000). Indroduction: Inventing Traditions [Introducción: Tradiciones inventadas]. En E. Hobsbawm y T. Ranger (Eds.), The invention of tradition [La invención de la tradición] (pp. 1-14). Cambridge, Estados Unidos: Cambridge University Press.

Horváth, H. (2016). Furniture and Interior Design [Muebles y diseño interior]. En J. Siza (Ed.), Motherland and Progress: Hungarian Architecture and Design 1800-1900 [Arquitectura y diseño húngaro 1800-1900] (pp. 740-758). Basilea, Suiza: Birkhäuser.

Ireland, K. (2006). Cythero Regained? The Rococo Revival in Europeon Literature and the Arts, 1830-1910 [¿Cythera recuperado? El renacmiento Rococó en la literatura y las artes europeas, 1830-1910]. Madison, Estados Unidos: Fairleigh Dickinson University Press. 
Itzigsohn, J. y vom Hau, M. (2006). Unfinished Imagined Communities: States, Social Movements, and Natinoalism in Latin America. Theory and Society, 25(2), 193-212.

Lasc, A. I. (2017). Paris, 1900. The Musée Centennal du Mobilier et de la Décoration and the formulation of a nineteenth-century national design identity [París, 1900. El museo centenario del mobiliario y de la Decoración y la formulación de una identidad nacional de diseño del siglo xIx]. En D. Raizman y E. Robey (Eds.), Exponding Nationalisms at World's Fairs. Identity, Diversity and Exchange 1851-1915 [Expandiendo los nacionalismos en las ferias mundiales. Identidad, diversidad e intercambio 1851-1915] (pp. 109-129). Londres, Inglaterra: Routledge.

Lenoir, N. P. (1958). Revolución, altitud 4000 metros. Ciudad Autónoma de Buenos Aires, Argentina: Cátedra Lisandro de la Torre.

Locker, T. (2017). Frederician Rococo at the Service of the German Empire: The 1900 Paris World's Fair and the Decorative Arts [Rococó Federiciano al servicio del Imperio Alemán: La Feria Mundial de París de 1900 y las Artes Decorativas]. Acto Artis. Estudisd'Art Modern, (45), 89-97. Recuperado de doi: https://doi.org/10.1344/actaartis.4-5.2017.19634

Meiner, J. (2014). Berliner Belle Époque. Der Ebenist Julius Zwiener und die Kunst möbel für den Hof Kaiser Wilhelms II. (1888-1918) [Berlín Belle Époque. El ebenista Julius Zwiener y los muebles de arte para la corte del emperador Guillermo II. (1888-1918)]. Petersberg, Alemania: Imhof.

Neveux, P. (1902). Classe 69: meubles de luxe et meubles à bon marché [Clase 69: muebles de lujo y baratos]. En Exposition universelle internationale de 1900 ò Paris: Ropports du jury international [1900 Exposición Universal Internacional de París: Informes del Jurado Internacional] (pp. 121-171). París, Francia: Imprimerie Nationale.

Payne, C. (2003). François Linke 1855-1946. The Belle Epoque of French Furniture [François Linke 1855-1946. La Belle Epoque de los muebles franceses]. Woodbridge, Inglaterra: Antique Collectors' club.

Sarmiento, D. F. [1845] (2007). Focundo o Civilización y Barbarie en las Pampas Argentinas. Ciudad Autónoma de Buenos Aires, Argentina: Gradifco.

Scarzanella, E. (1991). Devoto, Antonio. En Dizionario Biografico degli Italiani [Diccionario biográfico de los italianos] (pp. 603-605). Roma, Italia: Instituto della Enciclopedia Italiana \& Treccani.

Seidel, P. (1895). Die Metallbildhauer Friedrichs des Großen [Los escultores de metal de Federico el Grande]. Jahrbuch der preußischen Kunstsammlungen, XVI, 48-60.

Seidel, P. (1900). Die Sammlungen Friedrichs des Grossen, ausgestellt auf Allerhöchsten Befehl Seiner Majestät des Deutschen Kaisers [Las colecciones de Federico el Grande, expuestas por orden supremo de Su majestad el Emperador alemán]. En O. Witt (Ed.), Weltousstellung in Paris 1900. Amtlicher Katolog der Ausstellung des Deutschen Reichs 1900 [Exposición Universal de París 1900: Catálogo Oficial de la Exposición del Reich Alemán 1900] (pp. 61-65). Berlín, Alemania: Selbstverlag des Reichskommissariats.

Seidel, P. (1901). Für Seine Majestöt den Deutschen Kaiser angefertigte Kunstmöbel und Bronzen ouf der Pariser Weltousstellung 1900 [Muebles de Arte y Bronce en la Exposición Mundial de París de 1900 creados para Su Majestad el Emperador Alemán]. Berlín-Leipzig, Alemania: Giesecke \& Devrient. 
Seidel, P. (1912). Friedrich der Grosseund die bildende Kunst [Federico el Grande y las Bellas Artes]. Berlín-Leipzig, Alemania: Giesecke\&Devrient.

Shumway, N. (1993). La invención de la Argentina. Historia de una idea. Ciudad Autónoma de Buenos Aires, Argentina: Emecé.

Veblen, T. [1899] (1995). The Theory of the Leisure Closs [La teoría de la clase de ocio]. Nueva York, Estados Unidos: Dover Publications.

Witt, O. (Ed.) (1900). Weltousstellung in Paris 1900. Amtlicher Kotolog der Ausstellung des Deutschen Reichs [Exposición Universal de París 1900. Catálogo oficial de la exposición del Imperio Alemán] [Catálogo de exposición]. Berlín, Alemania: Selbstverlag des Reichskommissariats.

Zweig, M. (1924). Zweites Rokoko, Innenräumeund Housrät in Wienum 1830-1860 [Segundo Rococó. Interiores y aparatos domésticos en Viena hacia 1830-1860]. Viena, Austria: Kunstverlag Anton Schroll \& Co. 